\title{
COMMISSION 21: LIGHT OF THE NIGHT SKY \\ (LUMINESCENCE DU CIEL)
}

Report of Meeting, 24 August 1973

President: H. Elsässer.

\section{Business Meeting}

It was agreed that the Commission, in cooperation with Commissions 15 and 22, and the Dust Panel of COSPAR, should sponsor a colloquium on 'Interplanetary dust and the zodiacal light' which shall take place in Heidelberg in 1974 or 1975. New results of the space experiments being in orbit or being in preparation at the present time will represent one of the main topics of this colloquium.

With regard to a letter of Dr Weill on the problem of man-induced light and to the plans of the IAU-Executive Committee to form a new commission devoted to the protection of observatory sites the resolution was adopted:

"Commission 21 supports the creation of an IAU-working group on light pollution problems and is willing to assist in this work. Dr Weill has proposed a colloquium on this subject in Paris and we fully support this.'

\section{Scientific Meeting}

The following papers were presented:

R. Dumont and F. Sánchez-Martinez: From Zodiacal Light Photo-Polarimetry Around the Ecliptic to Phase Functions and Polarization Curves of Interplanetary Scatterer.

H. Elsässer: New results on the Zodiacal Light from Rocket- and Balloon-Measurements.

R. D. Wolstencroft: Recent work in Hawaii on Polarimetry of the Night Sky.

H. Tanabe: Integrated Star Light Derived from Star Counts. 